\title{
Damage to the Perirhinal Cortex Exacerbates Memory Impairment following Lesions to the Hippocampal Formation
}

\author{
Stuart Zola-Morgan, ${ }^{1,2}$ Larry R. Squire, ${ }^{1,2}$ Robert P. Clower, ${ }^{2}$ and Nancy L. Rempel ${ }^{3}$ \\ 'Veterans Affairs Medical Center, San Diego, California 92161 and ${ }^{2}$ Department of Psychiatry and ${ }^{3}$ Group in \\ Neurosciences, University of California at San Diego, La Jolla, California, 92093
}

Recent work has been directed at identifying the critical components of the medial temporal lobe that, when damaged, produce severe memory impairment. The $\mathbf{H}^{+} \mathbf{A}+$ lesion includes the hippocampal formation, the amygdala, and the adjacent entorhinal, parahippocampal, and perirhinal cortices. A more restricted medial temporal lobe lesion that includes the hippocampal formation and parahippocampal cortex (the $\mathrm{H}^{+}$lesion) produces less severe memory impairment. Previous work demonstrated that extending the $\mathrm{H}^{+}$lesion forward to include the amygdala did not exacerbate the impairment. Here, we tested the hypothesis that extending the $\mathrm{H}^{+}$lesion forward to include the perirhinal cortex (the $\mathrm{H}^{++}$lesion), but sparing the amygdala, should produce a more severe memory impairment and one that would approximate the level of memory impairment associated with the $\mathrm{H}^{+} \mathrm{A}+$ lesion. Monkeys with the $\mathrm{H}^{++}$lesion were severely impaired on two of three amnesia-sensitive tasks (delayed nonmatching to sample and delayed retention of object discrimination). On the third amnesia-sensitive task (concurrent discrimination learning), two of the monkeys in the $\mathrm{H}^{++}$group obtained poorer scores than all seven normal monkeys, although the overall group comparison was not significant. The memory impairment following $\mathrm{H}^{++}$damage was more severe overall than the impairment associated with the $\mathrm{H}^{+}$lesion and approached the level of impairment associated with the $\mathrm{H}^{+} \mathbf{A}+$ lesions. Quantitative measurement of damage in each anatomical component of the lesion indicated that the perirhinal cortex was the only brain region that was more extensively damaged in the $\mathrm{H}^{++}$group than in the $\mathrm{H}^{+}$group. These findings emphasize the importance of the perirhinal cortex in the anatomy of the medial temporal lobe memory system.

IKey words: memory, amnesia, monkey, hippocampus, perirhinal cortex, parahippocampal cortex, entorhinal cortex, amygdala, delayed nonmatching-to-sample task]

Received Apr. 8, 1992; revised July 9, 1992; accepted July 17, 1992

This work was supported by the Medical Research Service of the Department of Veterans Affairs, NIH Grant NS19063, the Office of Naval Research, and NIMH Postdoctoral Fellowship 1F32MH09989 to R.P.C. We thank D. G. Amaral and W. A. Suzuki for helpful discussions. We also thank C. M. LeClair and A. K. Lockwood for behavioral testing and technical assistance. A research protocol describing all aspects of the present study that related to the use of animals (care and maintenance, surgery, behavioral testing, and killing) was approved by the Animal Research Committees of the V. A. Medical Center, San Diego, and the University of California, San Diego.

Correspondence should be addressed to Stuart Zola-Morgan at the above address.

Copyright (C) 1993 Society for Neuroscience 0270-6474/93/130251-15\$05.00/0
Bilateral damage to the medial temporal lobe of the human brain causes a profound memory impairment (Scoville and Milner, 1957). Bilateral lesions of the medial temporal lobe in the monkey, intended to approximate the damage sustained in the human cases, also cause severe memory impairment (Mishkin, 1978; Mahut et al., 1981; Zola-Morgan and Squire, 1985) and reproduce many features of the memory impairment observed in amnesic patients (for reviews, see Zola-Morgan and Squire, 1990; Squire and Zola-Morgan, 1991). This medial temporal lobe lesion includes the hippocampal formation (i.e., the hippocampus proper, the dentate gyrus, the subicular complex, and the entorhinal cortex), the amygdala, as well as adjacent cortical regions that are necessarily damaged when the hippocampus and amygdala are removed using a direct surgical approach. We have termed this removal the $\mathbf{H}^{+} \mathbf{A}^{+}$lesion (Squire and ZolaMorgan, 1988), where $H$ refers to the hippocampus, $A$ to the amygdala, and + to the adjacent cortical regions.

Considerable work has been directed at identifying the critical components of the $\mathrm{H}^{+} \mathrm{A}^{+}$lesion, that is, the specific structures and connections that must be damaged to produce the full behavioral impairment. One important finding was that the $\mathrm{H}^{+} \mathrm{A}^{+}$ lesion produces greater memory impairment than the $\mathrm{H}^{+}$lesion, which damages the hippocampus proper, the dentate gyrus, the subicular complex, posterior entorhinal cortex, and parahippocampal gyrus (Mishkin, 1978; Mahut et al., 1982; Zola-Morgan and Squire, 1986; Zola-Morgan et al., 1989a). An early explanation of this finding was that the more severe deficit associated with $\mathrm{H}^{+} \mathrm{A}^{+}$lesions occurs because the amygdala is damaged in the large $\mathrm{H}^{+} \mathrm{A}^{+}$lesion but not in the more posterior $\mathrm{H}^{+}$lesion (Mishkin, 1978; Murray and Mishkin, 1984, 1986; Saunders et al., 1984). However, it was subsequently found that circumscribed bilateral lesions of the amygdala (the $A$ lesion), which spared underlying cortex, did not impair memory on any of four tasks. Moreover, the addition of the A lesion to the $\mathrm{H}^{+}$ lesion (i.e., an $\mathrm{H}^{+} \mathrm{A}$ lesion) produced no greater memory impairment than $\mathrm{H}^{+}$lesions alone (Zola-Morgan et al., 1989b).

Another possibility is that the severity of memory impairment produced by the $\mathrm{H}^{+} \mathrm{A}^{+}$lesion, in comparison to the $\mathrm{H}^{+}$lesion, is due to damage to cortex that underlies the amygdala. It is now appreciated that the cortical regions adjacent to the amygdala, which are damaged in the $\mathrm{H}^{+} \mathbf{A}+$ lesion but not in the $\mathbf{H}^{+}$ lesion, include not only anterior entorhinal cortex but also a substantial portion of perirhinal cortex (Zola-Morgan et al., $1989 \mathrm{c}$ ). In addition, the perirhinal cortex (areas 35 and 36) and the closely associated parahippocampal cortex (areas TH and TF) provide the major source of cortical inputs to the entorhinal cortex (Insausti et al., 1987) and also provide the major route through which the hippocampal formation can influence other 
cortical regions (Van Hoesen, 1982). Moreover, perirhinal cortex, in comparison to parahippocampal cortex, is a preferential target of unimodal visual information originating in area TE of neocortex (Suzuki et al., 1991). The entorhinal cortex in turn is the source of the perforant path, the major afferent projection to the dentate gyrus and the hippocampus.

We therefore reasoned that extending the $\mathrm{H}^{+}$lesion rostrally to include the anterior entorhinal cortex and perirhinal cortex, but sparing the amygdala (the $\mathrm{H}^{++}$lesion), should produce more memory impairment than is associated with the $\mathrm{H}^{+}$lesion and should approximate the level of memory impairment associated with the $\mathrm{H}^{+} \mathrm{A}^{+}$lesion. Accordingly, in the present study, we evaluated the severity of memory impairment in a group of monkeys with bilateral lesions that damaged the hippocampal formation, parahippocampal cortex, and perirhinal cortex, but spared the amygdala (the $\mathbf{H}^{++}$lesion). The performance of this group was compared with a group of monkeys with bilateral lesions that damaged the hippocampal formation and the parahippocampal cortex (the $\mathrm{H}^{+}$lesion), and a group of unoperated control monkeys (Zola-Morgan et al., 1992). Performance was tested on the delayed nonmatching to sample task within 6-8 weeks after surgery and again at least 1 year later. Performance was also assessed on two other tasks sensitive to human amnesia (delayed retention of object discriminations and eight-pair concurrent discrimination learning; Squire et al., 1988), and on two tasks analogous to ones that amnesic patients perform well (pattern discrimination learning and motor skill learning; Zola-Morgan and Squire, 1984).

\section{Materials and Methods}

Subjects

Behavioral findings from 17 cynomolgus monkeys (Macaca fascicularis) will be presented. All monkeys weighed between 2.9 and $4.7 \mathrm{~kg}$ at the beginning of behavioral testing and were estimated to be 3-5 years old, that is, young adults (Hartley et al., 1984; Szabo and Cowan, 1984).

The 17 monkeys belonged to three experimental groups. Initially, it was intended that seven monkeys receive bilateral $\mathrm{H}^{++}$lesions. During the period in which these animals were being prepared, we were able to modify the surgical approach to the anterior portion of the brain to provide better access to the anterior and ventral surfaces of the temporal lobe. Accordingly (as described below in Histological findings), five of the monkeys sustained substantial bilateral damage to the perirhinal cortex, while two monkeys sustained only mild damage to the perirhinal cortex (mean percentage damage $=13 \%$ ). These two monkeys, hereafter designated $\mathrm{H}^{+} 4$ and $\mathrm{H}^{+} 5$, were added to a group of three monkeys with $\mathrm{H}^{+}$lesions who had been tested previously and had also sustained only limited bilateral perirhinal damage (mean percentage damage $=12 \%$ ). In addition, one of the five $\mathrm{H}^{++}$monkeys who sustained more substantial perirhinal damage $\left(\mathrm{H}^{++5}\right)$ obtained anomalously good scores throughout testing, and this monkey's behavioral data were not included in the statistical analyses (see Behavioral findings for discussion). Thus, the $\mathrm{H}^{++}$group consisted of four monkeys (all males), and the $\mathrm{H}^{+}$group consisted of five monkeys (three females and two males). Behavioral data for three of the monkeys in the $\mathrm{H}^{+}$group $\left(\mathrm{H}^{+} \mathrm{l}-\mathrm{H}^{+} 3\right.$, all females) have been presented previously as part of four previous reports (referred to as the $\mathrm{H}^{+}$group in Zola-Morgan and Squire, 1986; Zola-Morgan et al., 1989a,b, 1992). The data for the remaining two monkeys in this group ( $\mathrm{H}^{+} 4$ and $\mathrm{H}+5$, both males) are reported here for the first time Seven unoperated monkeys (all males) served as a normal control group (N). Behavioral data for these seven monkeys have also been presented previously (Zola-Morgan et al., 1992). Finally, brain tissue from four additional animals was used as control material for histological analysis. These animals did not undergo behavioral testing.

\section{Surgery}

$H^{+}$, group. Animals were preanesthetized with ketamine hydrochloride (12-15 mg/kg, i.m.), intubated, and placed on a mechanical ventilator. Anesthesia was induced with isoflurane. Heart rate, blood pressure, and body temperature were monitored continuously, and the level of iso- flurane was adjusted as necessary to maintain a surgical plane of anesthesia. The monkey's head was positioned in a specially designed headholder that permitted unobstructed access to the temporal portion of the skull. The temporal muscles on each side were retracted, the zygomatic arch was removed, and openings were made on each side of the skull to expose much of the anterior and ventrolateral portions of the temporal lobe. Mannitol solution ( $2 \mathrm{gm} / \mathrm{kg}$, i.v.) was administered just prior to opening the dura in order to reduce brain volume and to allow better visualization of the ventromedial surface of the brain.

For the $\mathrm{H}^{++}$lesion, the intent was to remove the hippocampal formation bilaterally, including the hippocampus proper, the dentate gyrus, the subicular complex, and the entorhinal cortex (area 28). In addition, the removal was intended to include the perirhinal cortex (areas 35 and 36) and the parahippocampal cortex (areas TH and TF; von Bonin and Bailey, 1947; see Fig. 1). The perirhinal cortex extends $3-4 \mathrm{~mm}$ laterally from the rhinal sulcus and follows the rhinal sulcus rostrally and dorsally to the frontotemporal junction. In its most rostral and dorsal region, it consists of tissue that has been typically referred to as the temporal pole. For the portion of the lesion involving the perirhinal cortex, the intent was to remove approximately $3-4 \mathrm{~mm}$ of cortex lateral to the rostrocaudal extent of the rhinal sulcus as far anteriorly as the rostral pole of the amygdala (as anterior as the lesion could be effectively extended using our surgical approach). Based on our measurements of the cortical areas in the medial temporal region, we have estimated that the lesion, as intended, would encompass approximately $60 \%$ of the perirhinal cortex (see below). For the portion of the lesion involving the parahippocampal cortex, the medial bank of the occipitotemporal sulcus served as the lateral border (Fig. 1).

The pial surface over the intended lesion area was first cauterized, and brain tissue was then removed by suction using a glass pipette with an angled tip. The perirhinal cortex was removed first, and aspiration continued until the white matter below the cortical layer was exposed. The hippocampal formation including the entorhinal cortex and the parahippocampal cortex was then removed.

$\mathrm{H}^{+}$group. The surgical preparation for monkeys in the $\mathrm{H}^{+}$group was the same as that for the monkeys in the $\mathrm{H}^{++}$group except that the perirhinal cortex and the anterior entorhinal cortex werc not included in the removal. This surgery has been described in detail previously (Zola-Morgan and Squire, 1986; Zola-Morgan et al., 1989a).

\section{Behavioral testing}

All groups were allowed 6-8 weeks of recovery prior to the start of behavioral testing. Testing was carried out in a Wisconsin General Test Apparatus (Harlow and Bromer, 1938). During four to six daily sessions of pretraining, monkeys leamed to obtain food by displacing objects that covered any of three food wells located on a stimulus tray in front of the testing chamber. Five different tasks (described in detail in ZolaMorgan and Squire, 1984, 1985; Zola-Morgan et al., 1989b) were then administered to all monkeys in the order listed under Behavioral findings.

\section{Histological processing}

Animals were administered an overdose of pentobarbital sodium (Nembutal) and perfused transcardially with a buffered $0.9 \% \mathrm{NaCl}$ solution followed by at least 2 liters of $4 \%$ paraformaldehyde in $0.1 \mathrm{~m}$ phosphate buffer. The brains were then blocked in situ in the coronal plane, removed from the skull, cryoprotected in $50 \%$ glycerol, $50 \%$ ethylene glycol, and quick-frozen in isopentanc at $78^{\circ} \mathrm{C}$. Using a freezing microtome, $50 \mu \mathrm{m}$ coronal sections were then cut beginning at the temporal pole and continuing through a level caudal to the hippocampal formation. Every fifth section was mounted and stained with thionin to assess the extent of the lesions. To assess quantitatively the extent of damage to the cortical regions involved in the removals, that is, the perirhinal, entorhinal, and parahippocampal cortices, a mapping procedure was used as described below.

\section{Measurement of cortical areas in histological control animals}

The locations of the perirhinal, parahippocampal, and entorhinal regions are illustrated in Figure 1, which shows line drawings of representative coronal sections through the temporal lobe of $M$. fascicularis. Detailed cytoarchitectonic description of these regions is available in Amaral et al. (1987) and Insausti et al. (1987).

Using a projection microscope, tracings were made from the thioninstained sections from the four animals in the histological control group. 


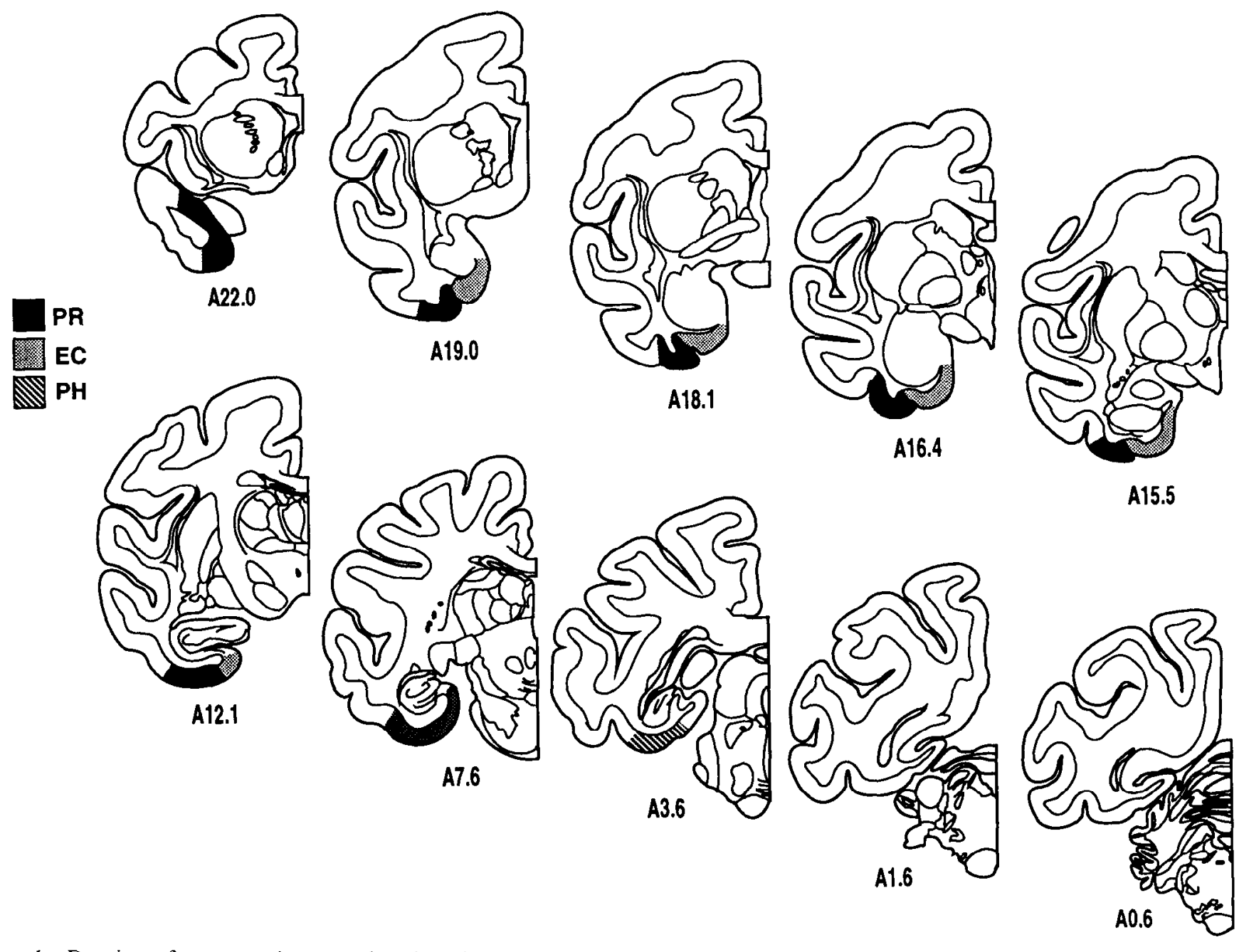

Figure 1. Drawings of representative coronal sections through the temporal lobe of $M$. fascicularis arranged from rostral (A22.0) to caudal (A0.6). The $\mathrm{H}^{++}$lesion in the present study was intended to remove all of the shaded regions, that is, the perirhinal cortex $(P R)$, the entorhinal cortex $(E C)$, and the parahippocampal cortex $(P H)$. Modified from Zola-Morgan et al. (1989c).

For each cortical region, areal tracings were made. The values from these tracings were averaged across all four control monkeys and were used as an estimate of the normal area for a given cortical region. Cortical areas were classified on the basis of cytoarchitectonic characteristics using a light microscope. Tracings of brain sections from the four histological control monkeys were made from the rostral extreme of the perirhinal cortex to the caudal extreme of the parahippocampal cortex. At rostral levels, the tracings extended from the fundus of the superior temporal sulcus laterally to the medial border of the entorhinal cortex (Fig. 1). At caudal levels, the tracings extended from the fundus of the superior temporal sulcus to the medial border of parahippocampal cortex. Cortical boundaries for the entorhinal, perirhinal, and parahippocampal cortices were marked on each tracing. A digitizing tablet was used to measure the length of each cortical region at each anterior-posterior level. The sum of these measurements multiplied by the interval between the sections provided an areal estimate for each cortical region. This same procedure was followed for both the left and right medial temporal lobes.

Determination of the amount of cortical damage. For each monkey in the two surgical groups, tracings of brain sections were used to measure the amount of tissue spared in each cortical region. For each traced section, the length (in millimeters) of spared cortex for a given region on the left and the right sides of the brain was averaged, and the mean of these lengths was recorded as the amount of spared cortex for that section. The mean lengths were then summed for all sections, and the total was multiplied by the section interval $(0.50 \mathrm{~mm})$ to estimate the mean amount of spared tissue in square millimeters. This valuc was then divided by the group mean for the same cortical region that was obtained from the histological control animals, thereby yielding an es- timate (from 0 to 1 ) of the proportion of spared tissue. This estimate was then subtracted from 1 and multiplied by 100 to obtain an estimate of the percentage of bilaterally damaged tissue. For example, animal $\mathrm{H}^{+}+2$ was estimated to have $63 \mathrm{~mm}^{2}$ of bilaterally spared perirhinal cortcx. This value was divided by the mean area of perirhinal cortex calculated from the histological control animals $\left(143 \mathrm{~mm}^{2}\right)$, to yield 0.44 as the proportion of bilaterally spared tissue, and $100(1-0.44)$ $=56$ as the percentage of perirhinal cortex damaged in animal $\mathrm{H}^{++} 2$. Due to the variation between monkeys in the sulcal patterns and surface areas within the temporal lobe, the amount of cortical damage in the animals with lesions are necessarily only estimates.

Determination of the amount of hippocampal damage. For each monkey in the two surgical groups, brain sections were examined at $1 \mathrm{~mm}$ intervals along the rostrocaudal extent of the hippocampus (range $=$ 12-15 sections). For each section, an estimate of the percentage damage to the hippocampus (including the dentate gyrus and the subicular complex) on the left and right sides was made by visual inspection and averaged to obtain an estimate of the overall percentage bilateral damage to the hippocampus at that level. The estimates of damage at all levels were then averaged to obtain an estimate of overall bilateral damage to the hippocampus.

\section{Results}

\section{Histological findings}

$\mathrm{H}^{++}$group. Figure 2 illustrates the damage in the monkeys in the $\mathrm{H}^{++}$group. In animal $\mathrm{H}^{++}$, the hippocampus was completely destroyed bilaterally, except for the caudalmost $3 \mathrm{~mm}$. 


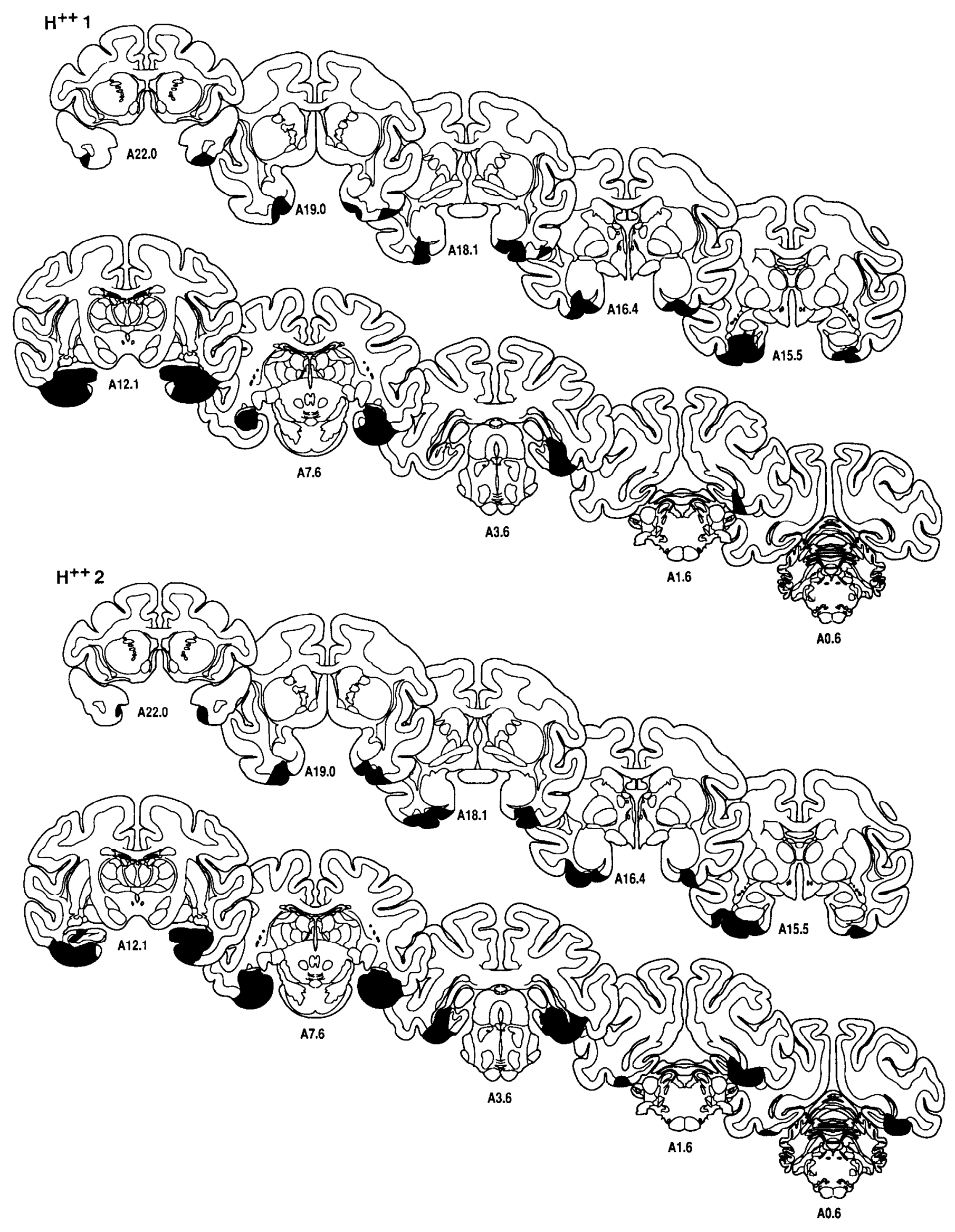




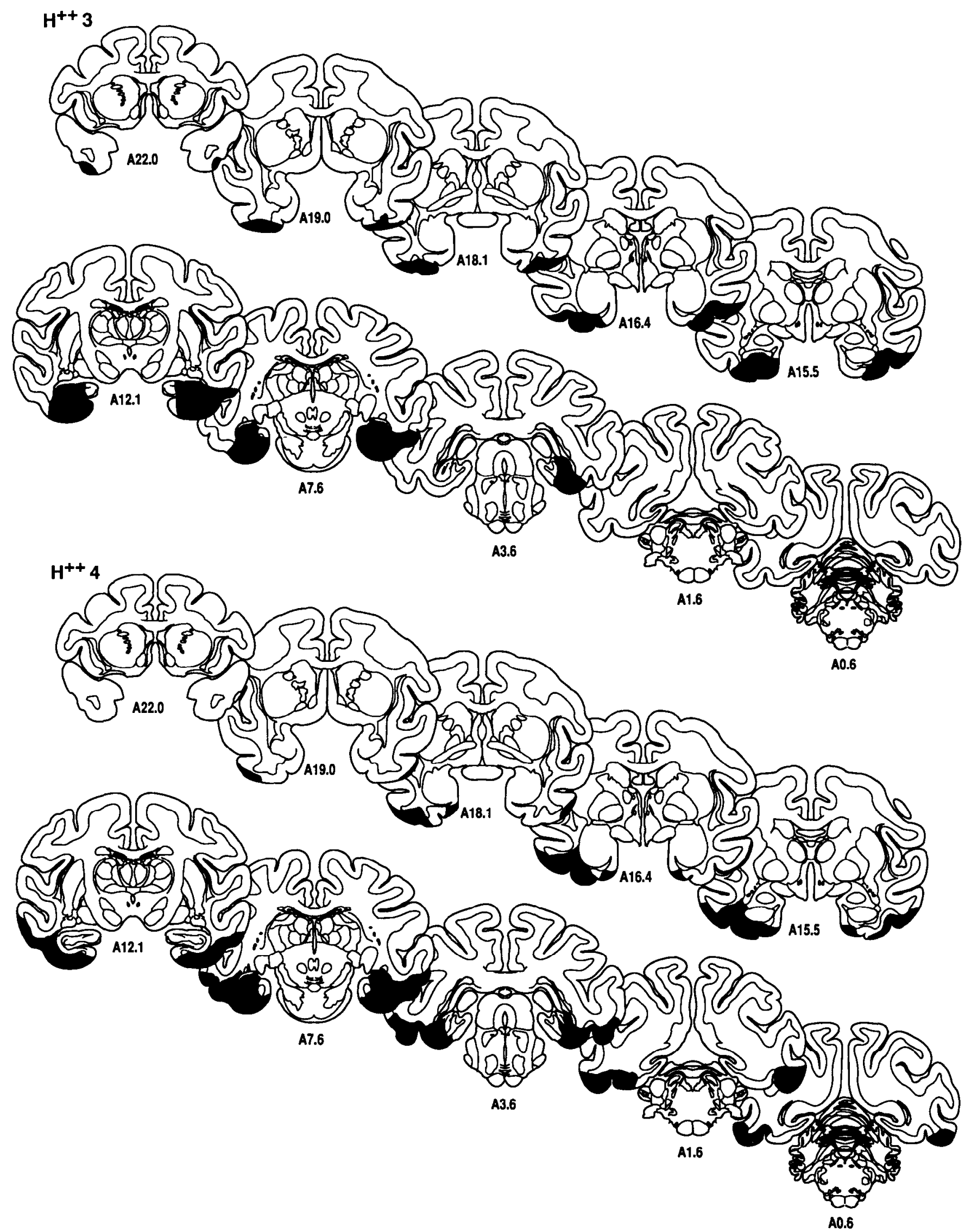

Figure 2. Representative coronal sections through the brains of four monkeys with the $\mathrm{H}^{++}$lesion. The anteroposterior level is indicated below each section, and the extent of damage is shown in black. Percentage bilateral damage to the perirhinal cortex for these four monkeys was estimated as $49 \%$ (see $\Gamma$ ig. 5). Vcry slight, unilateral amygdala damage was observed in two animals $\left(\mathbf{H}^{++} 1\right.$ and $\mathbf{H}^{++2}$ ). 

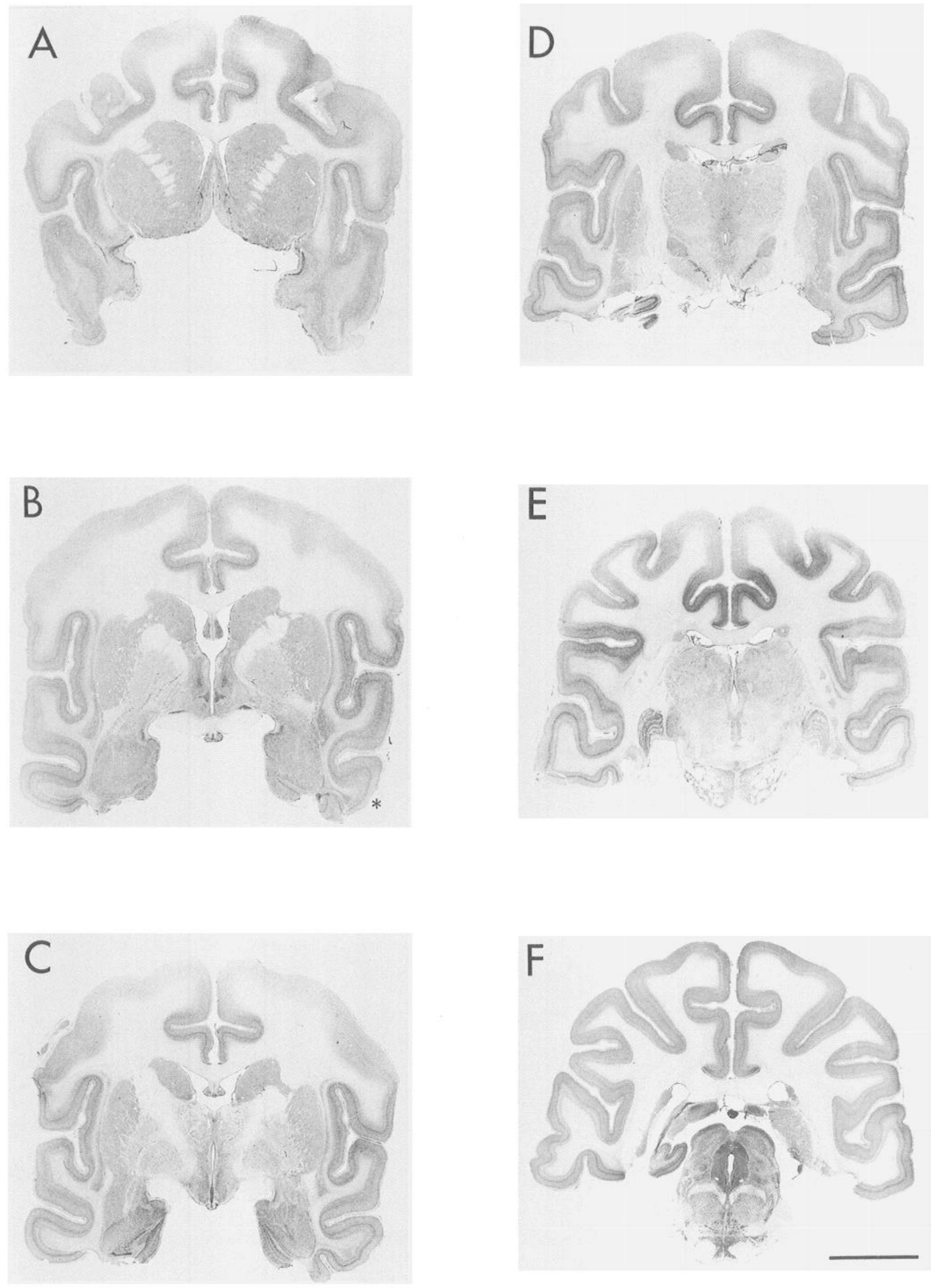
There was extensive bilateral damage to the perirhinal cortex adjacent and caudal to the amygdala. Damage to the entorhinal cortex was moderate to severe on both sides. In spared portions of the entorhinal cortex, layer II cells were almost completely absent on the right side, because of the loss of their targets in the ipsilateral dentate gyrus. However, on the left some cells were spared, corresponding to an area of intact dentate gyrus on the left side. Parahippocampal cortex was completely destroyed on the right side, but there was substantial sparing caudally on the left. There was very slight damage to the amygdala on the left side over most of its rostrocaudal extent, and the amygdala was entirely spared on the right side.

In animal $\mathrm{H}^{++} 2$ (Fig. 3), the hippocampus was completely destroyed bilaterally except for its rostralmost $3 \mathrm{~mm}$. The caudalmost $2 \mathrm{~mm}$ on the left side was also spared. The perirhinal cortex was extensively damaged on both sides, somewhat more than in monkey $\mathrm{H}^{++} 1$. This animal had somewhat less direct damage to entorhinal cortex than animal $\mathrm{H}^{++} 1$, but in the portions that were spared on both sides layer II was substantially depopulated. Parahippocampal cortex was severely damaged on the right sidc, but there was some sparing on the left. There was very slight damage to the caudal amygdala on the left side.

In animal $\mathrm{H}^{++}$, the hippocampus was completely destroyed bilaterally except for partial sparing on the left side over the rostralmost $4 \mathrm{~mm}$. There was some sparing of perirhinal cortex on the right side (less than one-third), but it was almost completely destroyed on the left. Entorhinal cortex damage was similar to that observed in animal $\mathrm{H}^{++}$, with layer II cells spared only on the left side, corresponding to a small area of intact dentate gyrus on the left. As in animal $\mathrm{H}^{++2}$, parahippocampal cortex damage was extensive on the right and somewhat less on the left. The amygdala was completely spared bilaterally.

In animal $\mathrm{H}^{++4}$, the hippocampus was extensively damaged bilaterally. The perirhinal cortex on the left side was completely destroyed caudal to the mid-amygdala. Damage to the perirhinal cortex on the right side began more caudally and was as extensive as on the left side. Entorhinal cortex damage was similar to that observed in animal $\mathrm{H}^{++}$, with layer II cells spared only on the left side, corresponding to a small area of intact dentate gyrus on the left. Parahippocampal cortex was completely destroyed bilaterally except for some sparing of its most medial aspect caudally. The amygdala was completely spared bilaterally.

In summary, the four $\mathrm{H}^{++}$monkeys sustained damage to at least two-thirds of the hippocampus bilaterally. Damage to perirhinal cortex caudal to the anterior pole of the amygdala was extensive bilaterally in all cases (see next section, Quantitative analysis of cortical and hippocampal damage). The temporal polar region of perirhinal cortex sustained only minimal damage. There was significant bilateral damage to the entorhinal cortex, including extensive depletion of cells in layer II in entorhinal cortex. Damage to parahippocampal cortex was moderate to extensive in these animals, except for $\mathrm{H}^{++}$, who had substantial sparing on one side. Only slight amygdala damage was observed in any of the $\mathrm{H}^{++}$animals. Damage to inferotem- poral cortex (area TE) ranged from minimal (monkey $\mathrm{H}^{++}$) to moderate (monkeys $\mathrm{H}^{++} 2-\mathrm{H}^{++} 4$ ) and was generally asymmetrical. Unilateral damage to the optic radiations and the lateral geniculate nucleus was also observed in two monkeys $\left(\mathrm{H}^{++2}\right.$ and $\mathbf{H}^{++3}$ ).

The damage in monkey $\mathrm{H}^{++5}$, for the most part, appeared similar to the other four $\mathrm{H}^{++}$monkeys with respect to the hippocampus, perirhinal cortex, entorhinal cortex, parahippocampal cortex, and area TE (see Quantitative analysis of cortical damage). On the right side, this monkey had an island of preserved tissue anteriorly that included portions of the perirhinal cortex, the entorhinal cortex, and the uncal portion of the hippocampus. In addition, a small portion of white matter was observed that connected the spared portions of entorhinal cortex and the hippocampus.

$\mathrm{H}^{+}$group. Detailed descriptions of damage in the three monkeys previously tested in this group $\left(\mathrm{H}^{+} \mathrm{l}-\mathrm{H}^{+} 3\right)$ have been published elsewhere (Zola-Morgan et al., 1989b) and will only be summarized here. Previous histological descriptions of this group of animals focused primarily on the extent of damage to the hippocampal formation and parahippocampal cortex. We reexamined the histological material from these monkeys in order to assess as well the extent of damage to the perirhinal cortex. Animals $\mathrm{H}^{+} 1$ and $\mathrm{H}^{+} 2$ sustained complete bilateral removal of the hippocampus proper, dentate gyrus, and subicular complex, as well as extensive bilateral damage to the entorhinal cortex. In the anterior portions of the entorhinal cortex that were spared, layer II cells were almost completely eliminated. Parahippocampal cortex in these two animals was extensively damaged bilaterally. In animal $\mathrm{H}^{+} 3$, approximately the anterior third of the hippocampal formation was spared. The entorhinal cortex was intact, but there was partial loss of layer II cells. There was also bilateral damage to the parahippocampal cortex, but this was not as extensive as in the other two monkeys. Perirhinal cortex was only slightly damaged in animals $\mathrm{H}^{+} 1$ and $\mathrm{H}^{+} 2$ and was almost entirely spared in animal $\mathrm{H}^{+} 3$.

Figure 4 illustrates the damage in monkeys $\mathrm{H}^{+} 4$ and $\mathrm{H}^{+5}$, the two monkeys that have not been described previously. Both animals had enlargements of the lateral ventricles that were asymmetrical. In monkey $\mathrm{H}^{+} 4$, the hippocampus was severely damaged throughout its rostrocaudal extent. The perirhinal cortex was almost entirely spared. A small posterior region of perirhinal cortex was severely damaged on the left side, and on the right it was compressed by the moderate enlargement of the lateral ventricle. The rostral three quarters of the entorhinal cortex was extensively damaged posteriorly. In the spared anterior portions of entorhinal cortex, there was significant cell loss in layer II. Parahippocampal cortex was completely destroyed bilaterally, except for $1-2 \mathrm{~mm}$ posteriorly. The posterior portion of area TE was moderately damaged on the left side and was largely spared on the right. The amygdala was entirely spared.

In monkey $\mathrm{H}^{+} 5$, the ventricular enlargement on the right side was substantial. The hippocampus was extensively damaged bilaterally. The perirhinal cortex was almost completely free of damage at all levels, although on the right side and over its

Figure 3. Photomicrographs of representative sections through the temporal lobe of monkey $\mathrm{H}^{++}+2$. The sections are arranged from rostral $(A)$ to caudal $(F)$. The lesion involved almost all of the perirhinal cortex bilaterally caudal to the anterior pole of the amygdala. Perirhinal cortex in the anterior temporal polar region sustained only minimal damage. Percentage bilateral damage to the perirhinal cortex for this animal was estimated as $56 \%$ (see text for details). The asterisk indicates damage produced in histological processing. Scale bar, $10 \mathrm{~mm}$. 


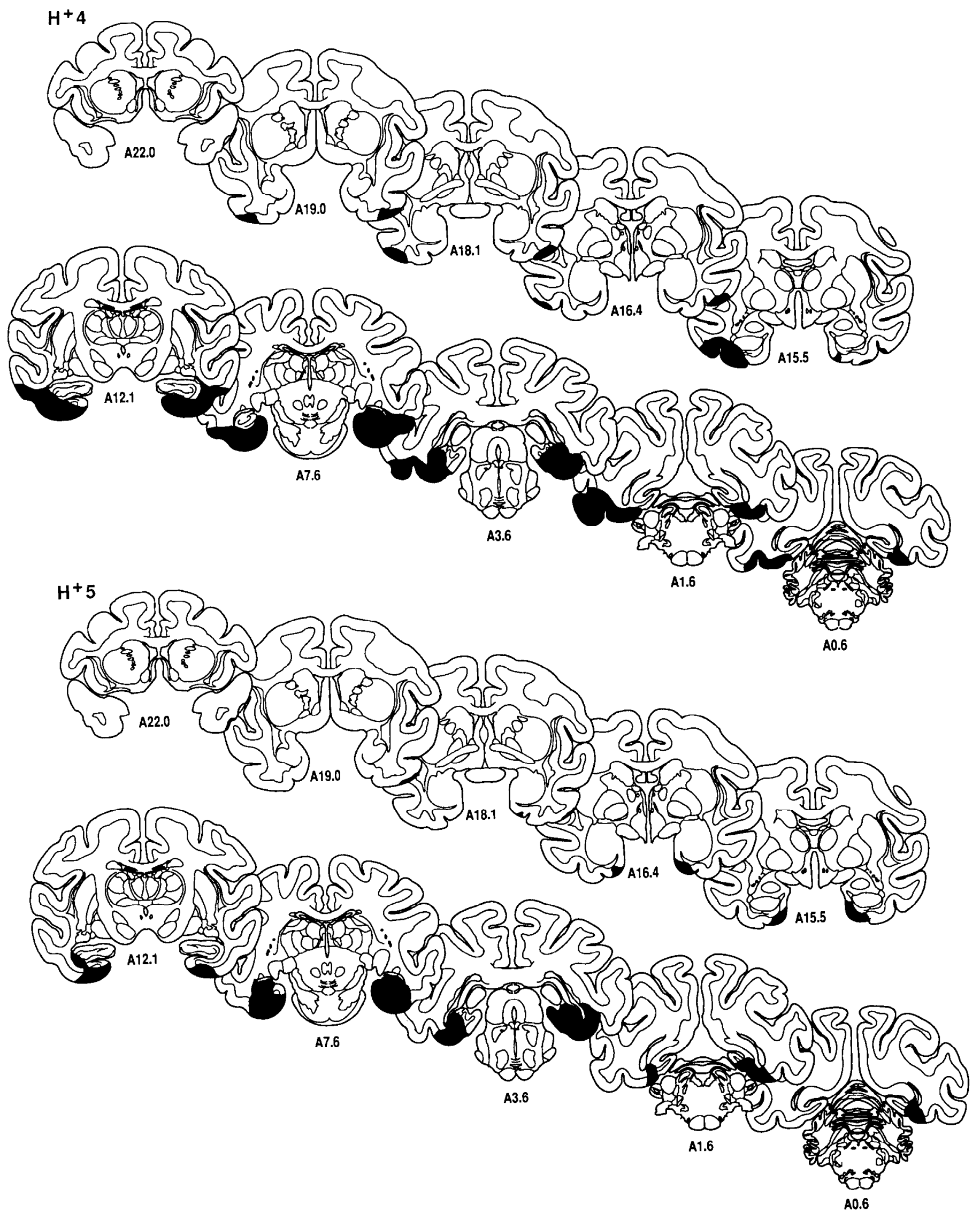

Figure 4. Representative coronal sections through the brains of monkeys $\mathrm{H}^{+} 4$ and $\mathrm{H}^{+}+5$. The anteroposterior level is indicated below each section, and the extent of damage is shown in black. Percentage bilateral damage to the perirhinal cortex in the $\mathrm{H}^{+}$group overall was estimated as $12 \%$ (see Fig. 4). 


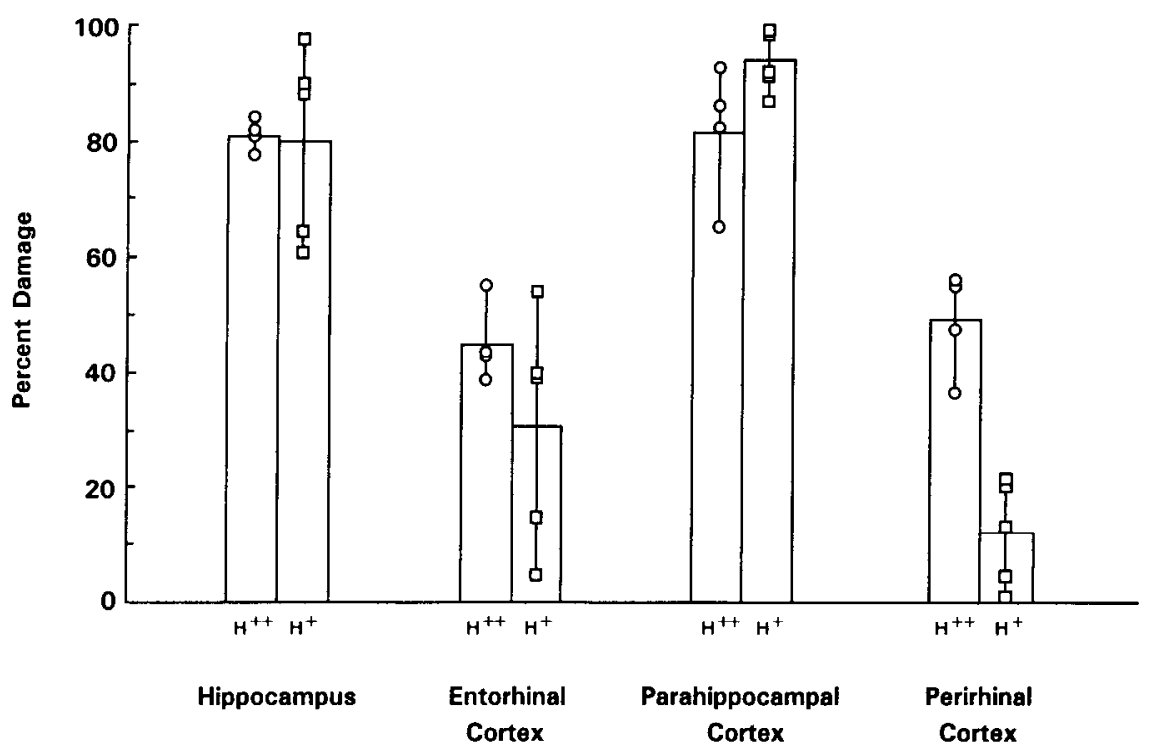

Figure 5. Estimates of percentage bilateral damage (mean of left and right sides) to three cortical regions (entorhinal cortex, parahippocampal cortex, and perirhinal cortex) were generated by tracing the intact cortex in monkeys with lesions and comparing these areas to the corresponding cortical areas in four unoperated control monkeys. Estimates of percentage bilateral damage to the hippocampus (mean of left and right sides) were made by visual inspection. For both lesion groups, comparable levels of damage were observed in entorhinal and parahippocampal cortices, as well as in the hippocampus. Monkeys with $\mathrm{H}^{++}$lesions, unlike monkeys with $\mathrm{H}^{+}$lesions, sustained considerable damage to the perirhinal cortex. caudal half it was somewhat compressed by the enlargement of the lateral ventricle. The posterior half of entorhinal cortex was moderately damaged, and there was significant depletion of cells in layer II in the spared regions. Parahippocampal cortex was almost completely destroyed bilaterally. Area TE was not directly damaged, but on the right side it was substantially compressed by the enlargement of the lateral ventricle. There was no damage or compression of the amygdala.

Quantitative analysis of cortical and hippocampal damage. Figure 5 shows the estimated percentage damage to the hippocampus and to the three cortical areas, that is, entorhinal cortex, parahippocampal cortex, and perirhinal cortex, for the two surgical groups. [The data for monkey $\mathrm{H}^{++} 5(80 \%, 40 \%$, $88 \%$, and $58 \%$, respectively) are not shown in Fig. 5.] The important point is that, as intended, damage to three of the anatomical components of the respective lesions (i.e., the hippocampus, entorhinal cortex, and parahippocampal cortex) was comparable in the $\mathrm{H}^{+}$and $\mathrm{H}^{++}$groups. However, damage to the perihinal cortex was extensive in the $\mathrm{H}^{++}$group and slight in the $\mathrm{H}^{+}$group.

The mean percentage damage to the hippocampus was $81 \%$ for the $\mathrm{H}^{++}$group (range $=78-84 \%$ ) and $80 \%$ for the $\mathrm{H}^{+}$group (rangc $=61-98 \% ; P>0.10$ ). The mcan pcrcentage damage to entorhinal cortex was $45 \%$ for the $\mathrm{H}^{++}$group (range $=38-56 \%$ ) and $30 \%$ for the $\mathrm{H}^{+}$group (range $=5-53 \% ; P>0.10$ ). The mean percentage damage to parahippocampal cortex was $81 \%$ for the $\mathrm{H}^{++}$group (range $=64-93 \%$ ) and $94 \%$ for the $\mathrm{H}^{+}$group (range $=87-99 \% ; P>0.05$ ). The mean percentage damage to perirhinal cortex was $49 \%$ for the $\mathrm{H}^{++}$group (range $=37-56 \%$ ) and $12 \%$ for the $\mathrm{H}^{+}$group (range $=1-22 \% ; P<0.001$ ).

\section{Behavioral findings}

Table 1 shows the performance scores for monkeys in the $\mathrm{N}$, $\mathrm{H}^{++}$, and $\mathrm{H}^{+}$groups on the three amnesia-sensitive tasks, that is, delayed nonmatching to sample (the scores are the average scores across two administrations of the test), delayed retention of object discrimination, and concurrent discrimination. Monkey $\mathrm{H}^{++} 5$ was not included in the statistical analyses based on two considerations. First, his scores were as good as or better than the scores of the normal monkeys (scores for $\mathrm{H}^{++} 5$ on the nine separate measures of Table 1: 440 trials, 0 trials, $91 \%, 85 \%$,
$86 \%, 83 \%, 85 \%, 84 \%, 160$ trials). Two striking examples of the unusually good performance of monkey $\mathrm{H}^{++} 5$ are worth noting. During the first administration of the delayed nonmatching to sample task, monkey $\mathrm{H}^{++5}$ obtained a score of $100 \%$ correct on the 10 min delay, a higher score than any of the $\mathrm{N}$ or $\mathrm{H}^{+}$ monkeys in the present study, and a higher score than any of the 74 other normal and operated monkeys that have been tested on the delayed nonmatching to sample task in our laboratory during the past 10 years. On the concurrent discrimination learning task, monkey $\mathrm{H}^{++5}$ required only 160 trials to reach criterion level performance, a better score than any of the $\mathrm{N}$ or $\mathrm{H}^{+}$monkeys in the present study, and a better score than 55 of 56 other normal and operated monkeys previously tested on the concurrent discrimination learning task in our laboratory.

Second, because it has been well established that even the more restricted $\mathrm{H}^{+}$lesion impairs performance significantly on the delayed nonmatching to sample task and on the other amnesia-sensitive tasks used in the present study (Mishkin, 1978; Mahut et al., 1982; Zola-Morgan et al., 1989a), the scores for monkey $\mathrm{H}^{++} 5$ do not clearly count for or against the hypothesis being tested, that is, that the $\mathrm{H}^{++}$lesion should produce more severe impairment than that observed after the $\mathrm{H}^{+}$lesion. That is, the scores for monkey $\mathrm{H}^{++} 5$ cannot reasonably be used to compare the severity of impairment associated with $\mathrm{H}^{+}$and $\mathrm{H}^{++}$lesions.

It is possible that the small, anterior, unilateral sparing of interconnected perirhinal, entorhinal, and hippocampal tissue could account for the anomalously good performance of monkey $\mathrm{H}^{++5}$. Although this possibility seems somewhat unlikely, the relative importance to memory function of specific portions of these regions and the white matter that underlies them, and the functional significance of residual tissue, has not been systematically examined. In any case, it is important to note that the findings for monkey $\mathrm{H}^{++} 5$ do raise a more general question concerning whether medial temporal lobe structures are always essential for performance on delayed nonmatching to sample and other tasks. This issue will be considered in the Discussion.

Finally, it is worth noting that the average scores of the $\mathrm{H}^{++}$ group would have been affected only slightly by the addition of monkey $\mathrm{H}^{++} 5$ (group mean scores without monkey $\mathrm{H}^{++} 5$ from Table 1 vs group mean scores with monkey $\mathrm{H}^{++5}$ : 1098 trials 
Table 1. Performance on tasks sensitive to amnesia

\begin{tabular}{|c|c|c|c|c|c|c|c|c|c|}
\hline \multirow[b]{3}{*}{ Group } & \multicolumn{7}{|c|}{ Delayed nonmatching to sample } & \multirow{3}{*}{$\begin{array}{l}\text { Object } \\
\text { retention }\end{array}$} & \multirow{3}{*}{$\begin{array}{l}\text { Concur- } \\
\text { rent } \\
\text { discrim- } \\
\text { ination }\end{array}$} \\
\hline & \multicolumn{2}{|c|}{ Trials to criterion } & \multicolumn{5}{|c|}{ Delays } & & \\
\hline & 1 & 2 & $8 \mathrm{sec}$ & $15 \mathrm{sec}$ & $60 \mathrm{sec}$ & $10 \mathrm{~min}$ & mean of 3 & & \\
\hline \multicolumn{10}{|l|}{ Normal } \\
\hline 1 & 180 & 0 & 92 & 93 & 88 & 73 & 85 & 88 & 240 \\
\hline 2 & 440 & 0 & 92 & 94 & 94 & 70 & 86 & 88 & 720 \\
\hline 3 & 220 & 0 & 91 & 93 & 88 & 79 & 87 & 85 & 640 \\
\hline 4 & 120 & 20 & 92 & 97 & 91 & 83 & 91 & 86 & 240 \\
\hline 5 & 180 & 0 & 91 & 94 & 85 & 75 & 85 & 85 & 360 \\
\hline 6 & 160 & 0 & 92 & 93 & 95 & 83 & 90 & 86 & 480 \\
\hline 7 & 80 & 80 & 91 & 84 & 88 & 86 & 86 & 87 & 600 \\
\hline Mean & 197 & 14 & 92 & 93 & 90 & 78 & 87 & 86 & 469 \\
\hline \multicolumn{10}{|l|}{$\mathrm{H}^{++}$} \\
\hline 1 & 1220 & 0 & 93 & 76 & 76 & 53 & 68 & 60 & 360 \\
\hline 2 & 1730 & 180 & 92 & 88 & 76 & 53 & 72 & 68 & 820 \\
\hline 3 & 940 & 280 & 91 & 74 & 68 & 57 & 66 & 78 & 300 \\
\hline 4 & 500 & 60 & 91 & 89 & 85 & 61 & 78 & 70 & 830 \\
\hline Mean & 1098 & 130 & 92 & 82 & 76 & 56 & 71 & 69 & 578 \\
\hline \multicolumn{10}{|l|}{$\mathrm{H}^{+}$} \\
\hline 1 & 260 & 20 & 91 & 89 & 73 & 65 & 75 & 75 & 760 \\
\hline 2 & 520 & 0 & 91 & 92 & 85 & 62 & 80 & 72 & 720 \\
\hline 3 & 840 & 0 & 91 & 93 & 92 & 64 & 83 & 80 & 880 \\
\hline 4 & 150 & 100 & 91 & 85 & 85 & 68 & 79 & 63 & 1510 \\
\hline 5 & 80 & 60 & 91 & 90 & 82 & 64 & 79 & 76 & 950 \\
\hline Mean & 370 & 36 & 91 & 90 & 83 & 65 & 79 & 73 & 964 \\
\hline
\end{tabular}

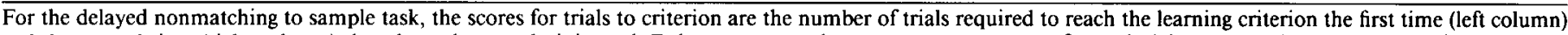

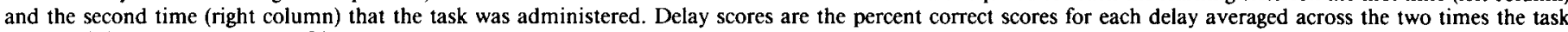

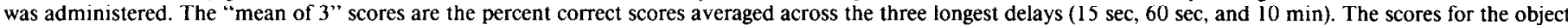

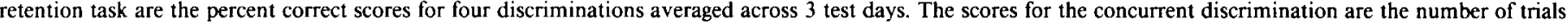
required to reach the learning criterion.

vs 966 trials, 130 trials vs 104 trials, $92 \%$ vs $92 \%, 82 \%$ vs $82 \%$, $76 \%$ vs $78 \%, 56 \%$ vs $61 \%, 71 \%$ vs $74 \%, 69 \%$ vs $72 \%, 578$ trials vs 494 trials).

1. Delayed nonmatching to sample. This task was administered to all the groups on two different occasions. The first administration occurred 6-8 weeks after surgery, immediately after the completion of pretraining, and the second administration occurred after completion of testing on three other tasks (pattern discrimination, delayed retention of object discriminations, and eight-pair concurrent discrimination learning). The interval between the first and second administrations of the nonmatching task was 6-9 months for the normal monkeys, 12-18 months for the $\mathrm{H}^{++}$group, and 18-41 months for the $\mathrm{H}^{+}$group. [Just prior to the second administration of the delayed nonmatching task, the three original monkeys in the previously tested $\mathrm{H}^{+}$group $\left(\mathrm{H}^{+} \mathbf{1}-\mathrm{H}^{+} 3\right)$ had been given a different version of the nonmatching task that involved introducing a distracting event during some of the delay trials (Zola-Morgan et. al., 1989a).]

Basic task ( 8 sec delay). On the first administration of the delayed nonmatching task, two of the four monkeys in the $\mathrm{H}^{++}$ group (monkeys $\mathrm{H}^{++} 1$ and $\mathrm{H}^{++}$) were unable to reach the criterion level of performance on the basic task $(90 \%$ correct during 100 consecutive trials) within 1140 trials of testing. These two monkeys averaged $70 \%$ correct during their last 100 trials. At this point, the testing procedure was modified so that the sample stimulus was presented twice in succession instead of only once (Aggleton and Mishkin, 1983). Only one of the two sample presentations was rewarded, and which sample presen- tation was rewarded was determined randomly for each trial. With the benefit of double-sample presentation, animal $\mathrm{H}^{++}$ was able to reach criterion after an additional 80 trials (total trials, 1220), and animal $\mathrm{H}^{++} 2$ was able to reach learning criterion after an additional 590 trials (total trials, 1730). Monkeys $\mathrm{H}^{++} 3$ and $\mathrm{H}^{++} 4$ learned the task in 940 trials and 500 trials, respectively, using the standard testing procedure. The mean score for the $\mathrm{H}^{++}$group was 1098 trials. On the second administration of the nonmatching task, all $\mathrm{H}^{++}$monkeys relearned the task more quickly and without requiring the double-sample presentation procedure (mean trials to criterion, 130).

Figure $6 A$ shows the mean number of trials required to learn the basic ( $8 \mathrm{sec}$ ) task on the first (open bars) and second (solid bars) administration. On the first administration of the task, the two operated groups were impaired $(P \mathrm{~s}<0.05)$. The $\mathrm{H}^{++}$group required more trials to reach criterion than the $\mathrm{H}^{+}$group [1098 trials vs 370 trials, respectively; $t(4)=2.6 ; P<0.05]$. On the second administration of the task, both the $\mathrm{H}^{++}$group and the $\mathrm{H}^{+}$group required numerically more trials than normal monkeys to reach criterion (130, 36, and 14 trials, respectively). None of these differences was statistically significant $\left(P_{\mathrm{S}}>0.10\right)$.

Delays (15 sec, $60 \mathrm{sec}, 10 \mathrm{~min}$ ). All groups performed similarly on the first and second tests at all three delay intervals. For example, at the $10 \mathrm{~min}$ delay, the scores for the first and second tests were, for the $\mathrm{N}$ group, $79 \%$ and $77 \% ; \mathrm{H}^{++}, 62 \%$ and $50 \%$; and $\mathrm{H}^{+}, 66 \%$ and $63 \%$ (all $P \mathrm{~S}>0.10$ ). Accordingly, for each monkey the performance scores for the first and second tests were averaged together to evaluate performance across delays. 
A

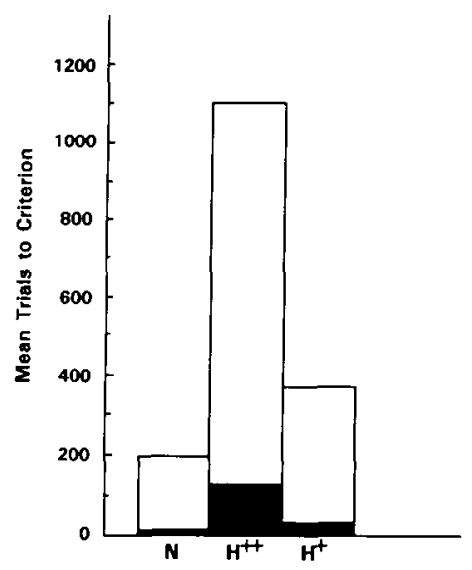

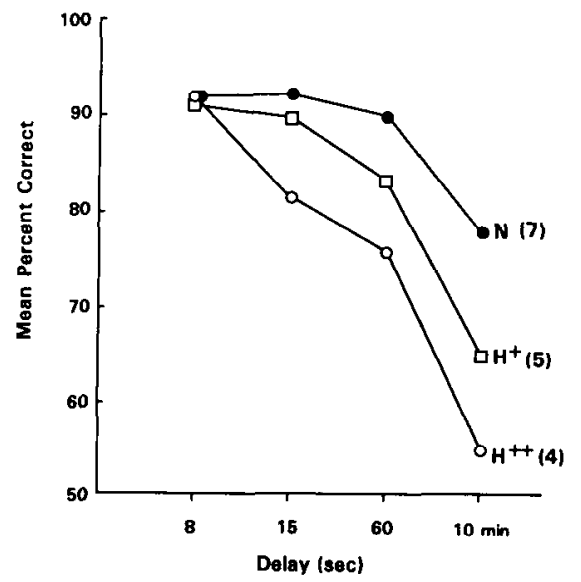

Figure 6. Performance on the delayed nonmatching to sample task on two different occasions for normal monkeys $(N)$, monkeys with lesions of the hippocampal formation, parahippocampal cortex, and perirhinal cortex $\left(\mathrm{H}^{++}\right)$, and monkeys with lesions of the hippocampal formation and the parahippocampal cortex $\left(H^{+}\right) . A$, Initial learning of the task with a delay of 8 sec (see Table 1 for trials to criterion for individual animals; first test, open bars, second test, solid bars). $B$, Performance across delays for the same groups. For each monkey, performance scores on the two tests were averaged together. The performance curve for the $\mathrm{H}^{++}$group probably underestimates the deficit, because one of the four animals in this group required a remedial procedure in which the sample object was always presented twice instcad of once (see Results for details).
(On the delay portion of the nonmatching task, monkey $\mathrm{H}^{++} \mathrm{I}$ required double-sample presentation on the first administration but not on the second administration.)

Figure $6 B$ shows performance across delays. A two-way ANOVA (three groups, three delays) revealed a significant effect of group $[F(2,15)=28.4 ; P<0.001]$, delay $[F(2,32)=91.9 ; P<$ $0.001]$, and group $\times$ delay interaction $[F(4,32)=3.5 ; P<0.05]$. Separate comparisons based on each group's scores averaged across the three longest delays ( $15 \mathrm{sec}, 60 \mathrm{sec}, 10 \mathrm{~min}$ ) revealed that both operated groups were impaired ( $l \mathrm{~s}>5.0 ; P \mathrm{~s}<0.001)$. Importantly, the $\mathrm{H}^{++}$group was significantly more impaired than the $\mathrm{H}^{+}$group [mean percentage correct: $\mathrm{H}^{++}=71 \%, \mathrm{H}^{+}=$ $79 \% ; t(7)=2.9, P<0.05]$. The same pattern of findings was observed when the groups were compared at the 10 min delay. Both surgical groups were impaired $(t \mathrm{~s}>2.9 ; P \mathrm{~s}<0.05)$, and the $\mathrm{H}^{++}$group (mean percentage correct $=56 \%$ ) was significantly more impaired than the $\mathrm{H}^{+}$group (mean percentage correct $=65 \% ; P<0.01)$.

In summary, the $\mathrm{H}^{++}$lesion produced a level of impairment on the delayed nonmatching task that was more severe than the level of impairment associated with the $\mathrm{H}^{+}$lesion. Moreover, the $\mathrm{H}^{++}$lesion produced an enduring impairment. Performance on the delay portion of the delayed nonmatching to sample task was just as impaired when the task was administered the second time as when it was first administered 1.5 years earlier.

2. Pattern discrimination. The number of trials required to learn the two pattern discrimination problems were averaged for each monkey (Fig. 7). Monkey N1 performed continually at chance level on both problems, and testing on each problem was discontinued after 1000 trials. This animal was assigned a score of 1000 trials. Monkey N3 also performed continually at chance level on the first problem, and testing was discontinued after 1000 trials. On the second problem, N3 obtained a score of 720 trials. This animal was assigned a score of 860 trials, the mean of the scores obtained on the two problems. (Monkey $\mathrm{N} 1$ and N3 were referred to as N4 and N6 in Zola-Morgan et al., $1989 \mathrm{c}$.) There were no differences between any of the groups in terms of the number of trials required to learn the pattern discrimination problems $(P \mathrm{~S}>0.10)$.

3. Delayed retention of object discriminations. The data for all four discriminations were averaged together for each animal. Overall performance, averaged across all three days of testing (Fig. 8, Table 1), showed that both surgical groups were impaired
( $\mathrm{N}=86 \%$ correct, $\left.\mathrm{H}^{++}=69 \%, \mathrm{H}^{+}=73 \% ; P \mathrm{~s}<0.001\right)$. The $\mathrm{H}^{++}$group obtained a numerically poorer score than the $\mathrm{H}^{+}$ group, but this difference did not reach statistical significance $(P>0.10)$.

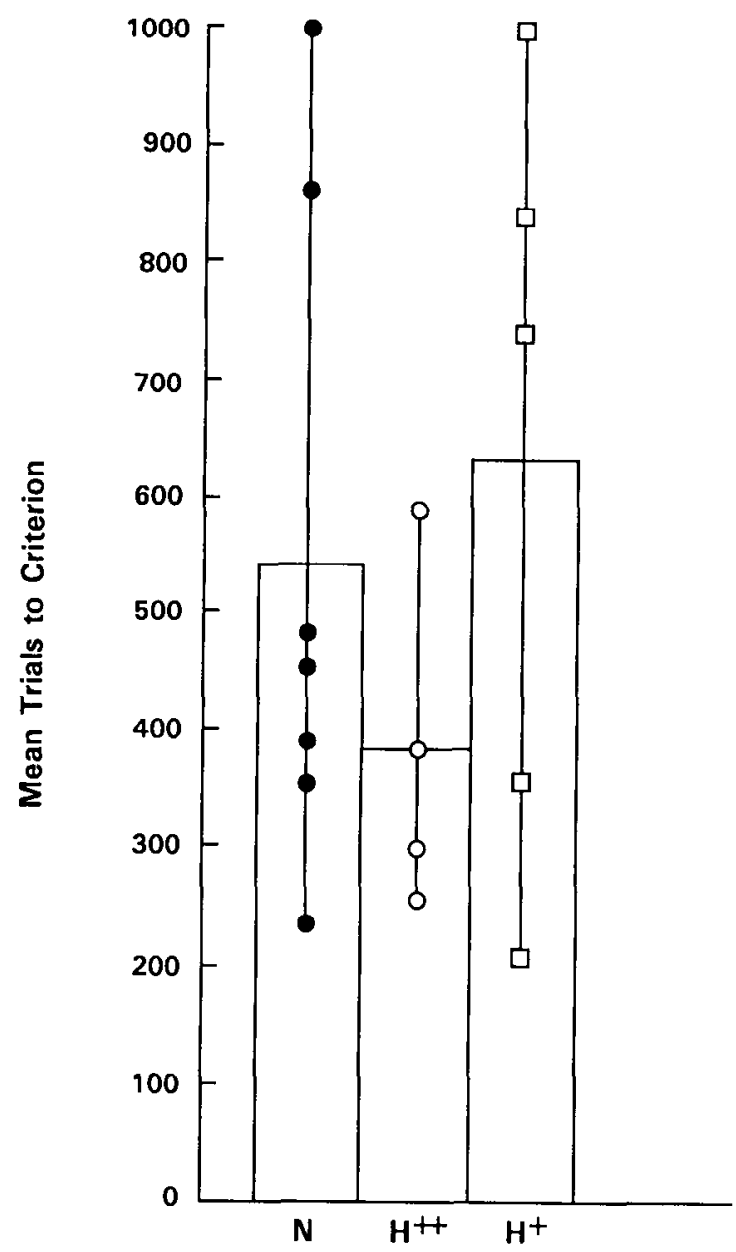

Figure 7. Average score on two pattern discrimination tasks by normal monkeys $(N)$, monkeys with lesions of the hippocampal formation, parahippocampal cortex, and perirhinal cortex $\left(\mathrm{H}^{++}\right)$, and monkeys with lesions of the hippocampal formation and the parahippocampal cortex $\left(\mathrm{H}^{+}\right)$. Symbols show scores for individual monkeys. 


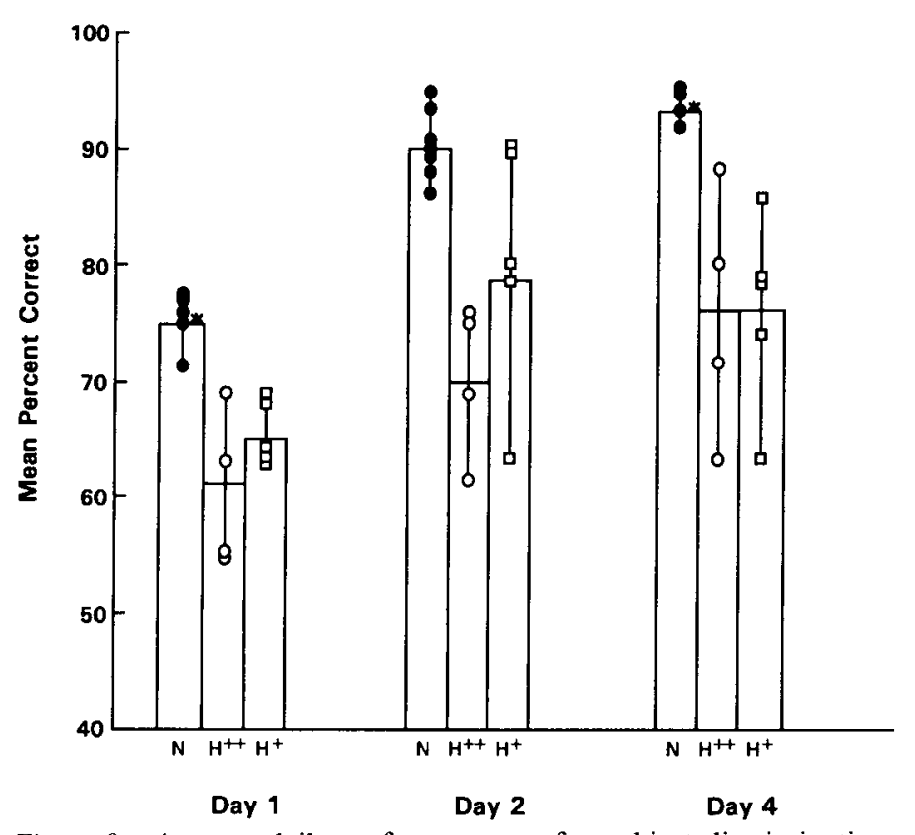

Figure 8. Average daily performance on four object discrimination tasks for normal monkeys $(N)$, monkeys with lesions of the hippocampal formation, parahippocampal cortex, and perirhinal cortex $\left(H^{++}\right)$, and monkeys with lesions of the hippocampal formation and the parahippocampal cortex $\left(\mathrm{H}^{+}\right)$. Symbols show scores for individual monkeys. *, Day 1 , indicates three animals who obtained a score of $75 \%$ correct:

*, Day 4, indicates four animals who obtained a score of $93 \%$ correct.

Another way of describing these data is to note that all monkeys were able to achieve a run of 9 out of 10 correct trials by the end of day 2 of testing. Normal monkeys required a median of 11 trials to learn the four tasks (medians are used here to permit direct comparisons with the findings reported in ZolaMorgan and Squire, 1985, and Zola-Morgan et al., 1989a,b), $\mathrm{H}^{+}$monkeys required 20 trials, and $\mathrm{H}^{++}$monkeys required 29 trials. By this measure, both surgical groups were impaired $(P \mathrm{~s}$ $<0.01$ ). While monkeys in the $\mathrm{H}^{++}$group required more trials to obtain 9 out of 10 correct trials than did the monkeys in the $\mathrm{H}^{+}$group, this difference did not reach statistical significance.

4. Concurrent discrimination. The scores for each group are presented in Figure 9. Although both surgical groups required numerically more trials than the normal group to reach criterion (mean trials: $\mathrm{N}=469, \mathrm{H}^{++}=578, \mathrm{H}^{+}=964$ ), only the comparison between the $\mathrm{H}^{+}$group and the normal group reached statistical significance $(P<0.001)$. Two of the four monkeys in the $\mathrm{H}^{++}$group required more trials than any of the seven monkeys in the normal group to reach criterion on the concurrent task. The other two monkeys in the $\mathrm{H}^{++}$group obtained scores in the normal range (Table 1). The $\mathrm{H}^{+}$and the $\mathrm{H}^{++}$groups were not significantly different $(P>0.10)$.

5. Lifesaver motor skill. All monkeys learned the Lifesaver task at a similar rate. A two-way ANOVA (three groups, eight test days) revealed a significant effect of session $[F(7,128)=$ 23.7; $P<0.01]$, indicating that performance improved across test days. There was no effect of group and no interaction $(F \mathrm{~s}$ $<1.0$; monkey $\mathrm{H}^{++} \mathbf{3}$ was killed prior to the administration of this task, so data are reported for only three $\mathrm{H}^{++}$monkeys). One month after the final session of initial learning, all groups showed excellent retention of the task.

\section{Discussion}

Monkeys with bilateral lesions of the hippocampal formation and the parahippocampal cortex plus the perirhinal cortex (the

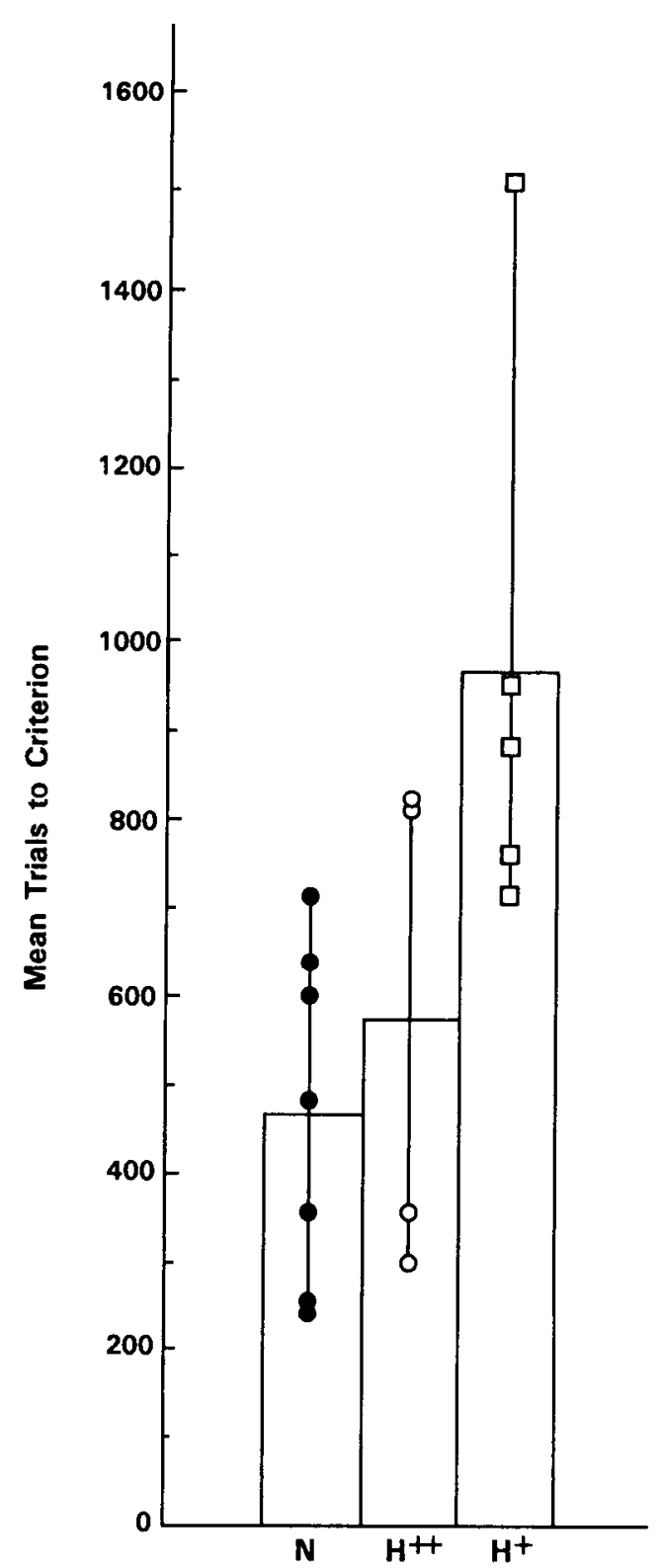

Figure 9. Performance on the eight-pair concurrent discrimination task by normal monkeys $(N)$, monkeys with lesions of the hippocampal formation, parahippocampal cortex, and perirhinal cortex $\left(H^{++}\right)$, and monkeys with lesions of the hippocampal formation and the parahippocampal cortex $\left(\mathrm{H}^{+}\right)$. Symbols show scores for individual monkeys.

$\mathrm{H}^{++}$lesion) were severely impaired on two of three amnesiasensitive tasks (delayed nonmatching to sample and delayed retention of object discriminations). On the third amnesia-sensitive task (concurrent discrimination learning), two of the four monkeys in the $\mathrm{H}^{++}$group obtained poorer scores than all seven normal monkeys, although the overall group comparison was not significant. The memory impairment following $\mathrm{H}^{++}$damage was enduring. When monkeys with $\mathrm{H}^{++}$lesions were retested on the delayed nonmatching to sample task, they performed as poorly at all three delay intervals as they had when first tested 1.5 years earlier. Importantly, the monkeys with $\mathrm{H}^{++}$lesions learned the two pattern discriminations normally and they werc normal at learning and retaining the lifesaver motor skill task. Thus, despite being impaired on tasks that are sensitive to human amnesia, the monkeys with $\mathrm{H}^{++}$lesions performed nor- 
mally on tasks analogous to ones that amnesic patients do not fail.

The memory impairment of the $\mathrm{H}^{++}$monkeys was more severe overall than the impairment associated with surgical lesions of the hippocampal formation and the parahippocampal cortex that did not include significant damage to the perirhinal cortex (the $\mathrm{H}^{+}$group). On the delayed nonmatching to sample task, the $\mathrm{H}^{++}$group was significantly more impaired than the $\mathrm{H}^{+}$group, as measured by initial learning as well as by performance on the delay portions of the task. In addition, the $\mathrm{H}^{++}$ group was numerically more impaired than the $\mathrm{H}^{+}$group on two separate measures of the delayed retention of object discriminations, although these comparisons did not reach statistical significance. On the third task, the performance of $\mathrm{H}^{++}$ monkeys did not differ from that of the $\mathrm{H}^{+}$monkeys.

The perirhinal cortex was the only brain region that was more extensively damaged in the $\mathrm{H}^{++}$group than in the $\mathrm{H}^{+}$group (Fig. 5). Each of the other regions involved in the two lesion groups (i.e., the hippocampus proper, including the dentate gyrus and the subicular complex, the entorhinal cortex, and the parahippocampal cortex) was comparably damaged in the two groups. Accordingly, the finding that monkeys with $\mathrm{H}^{++}$damage were overall more impaired than monkeys with $\mathrm{H}^{+}$damage points to the importance for memory of the perirhinal cortex. This region presumably participates in memory functions by virtue of its extensive reciprocal connections with widespread regions of neocortex (Van Hoesen and Pandya, 1975; Witter et al., 1989; Suzuki et al., 1991), which are putative sites of memory storage (Squire and Zola-Morgan, 1991). Importantly, the perirhinal cortex does not simply connect the neocortical regions to the hippocampus. Instead, the perirhinal cortex must play an important role in memory on its own as evidenced by the fact that memory impairment is increased when the perirhinal cortex is added to the $\mathrm{H}^{+}$lesion. This idea is consistent with previous work from our laboratory (Lola-Morgan et al., 1989c; Squire and Zola-Morgan, 1991; Zola-Morgan and Squire, 1993) as well as the work by others (Horel ct al., 1987; Murray et al., 1989; Murray, 1992).

$\mathrm{H}^{++}$group versus $H^{+} A$ group. It is useful to compare the findings from the $\mathrm{H}^{++}$group to the findings for monkeys with $\mathrm{H}^{+} \mathrm{A}$ lesions (Zola-Morgan et al., 1989b). As indicated by the terminology, both groups have in common the $\mathrm{H}^{+}$lesion, that is, damage to the hippocampus (including the dentate gyrus and the subicular complex), the entorhinal cortex, and the parahippocampal cortex. In the $\mathrm{H}^{+} \mathrm{A}$ lesion, however, the $\mathrm{H}^{+}$lesion is extended forward to include the amygdala, leaving the perirhinal cortex intact, while in the $\mathrm{H}^{++}$lesion, the perirhinal cortex is added to the $\mathrm{H}^{+}$lesion, leaving the amygdala intact. Previous work showed that adding amygdala damage to the $\mathrm{H}^{+}$lesion (the $\mathrm{H}^{+} \mathrm{A}$ lesion) did not exacerbate the impairment observed following $\mathrm{H}^{+}$damage alone (Zola-Morgan et al., 1989b). In contrast, as shown by the present findings, adding perirhinal damage to the $\mathrm{H}^{+}$lesion did exacerbate the $\mathrm{H}^{+}$impairment. A direct comparison of the performance of the $\mathrm{H}^{++}$and $\mathrm{H}^{+} \mathrm{A}$ groups reinforces this point. Overall, the $\mathrm{H}^{++}$group was more impaired than the $\mathrm{H}^{+} \mathrm{A}$ group.

On the $10 \mathrm{~min}$ delay interval of the delayed nonmatching to sample task (averaged across two administrations of the test), the $\mathrm{H}^{++}$group performed worse than the $\mathrm{H}^{+} \mathrm{A}$ group [56\% vs $68 \%$ correct, respectively; $t(5)=4.2, P<0.01]$. The $\mathrm{H}^{++}$group was also numerically worse than the $\mathrm{H}^{+} \mathrm{A}$ group when the scores on the delayed nonmatching to sample task were averaged across the three longest delays ( $71 \%$ vs $76 \%$ correct, respectively), and when performance on the delayed retention of object discriminations was averaged across the $3 \mathrm{~d}$ of testing (69\% vs $72 \%$ correct, respectively). On the concurrent discrimination task, the two monkeys in the $\mathrm{H}^{++}$group with impaired scores $(820$ and 830 trials) performed worse than any of the three monkeys in the $\mathrm{H}^{+} \mathrm{A}$ group (520, 720, and 720 trials). These comparisons, together with previous findings (7ola-Morgan et al., 1989b,c) underscore the important role in memory of perirhinal cortex and also indicate the lack of involvement of the amygdala in the kinds of memory function evaluated here (Squire and ZolaMorgan, 1991; Zola-Morgan and Squire, 1993).

$\mathrm{H}^{++}$group versus $\mathrm{H}^{+} \mathrm{A}^{+}$group. The findings from the $\mathrm{H}^{++}$ group can also be usefully compared to the findings for monkeys with $\mathrm{H}^{+} \mathbf{A}^{+}$lesions (Zola-Morgan et al., 1982, 1984, 1985). Studies of memory impairment in monkeys began with large medial temporal lobe removals intended to approximate the damage in amnesic patient H.M. (the $\mathrm{H}^{+} \mathrm{A}^{+}$lesion). As indicated by the terminology, the $\mathrm{H}^{+} \mathrm{A}^{+}$lesion damages the hippocampus (including the dentate gyrus and the subicular complex), the amygdala, the perirhinal cortex, the entorhinal cortex, and the parahippocampal cortex. The $\mathrm{H}^{+} \mathrm{A}^{+}$lesion produces severe memory impairment (Mishkin, 1978; Mahut et al., 1981; Zola-Morgan and Squire, 1985). Our neurohistological processing of the $\mathrm{H}^{+} \mathrm{A}^{+}$ brains (Zola-Morgan and Squire, 1985), carried out more than 10 years before the present study, did not permit a detailed, quantitative evaluation of the extent of perirhinal damage. It was clear, however, that each of the $\mathrm{H}^{+} \mathrm{A}^{+}$monkeys sustained significant bilateral damage to the perirhinal cortex (Zola-Morgan et al., 1989c).

The portion of perirhinal cortex that was damaged was different to some extent in the $\mathrm{H}^{++}$monkeys and the $\mathrm{H}^{+} \mathrm{A}^{+}$monkeys. First, the neurosurgical approach used to remove the amygdala in the $\mathrm{H}^{+} \mathrm{A}^{+}$monkeys necessarily damaged the temporal polar portion of the perirhinal cortex, but this portion was almost entirely spared in the $\mathrm{H}^{++}$monkeys. Second, the lesions in the $\mathrm{H}^{+} \mathrm{A}^{+}$monkeys spared some laterally situated perirhinal cortex (area 36), but this portion of perirhinal cortex was consistently damaged in the $\mathrm{H}^{++}$monkeys. Finally, the $\mathrm{H}^{+} \mathrm{A}^{+}$monkeys sustained greater overall damage than did the $\mathrm{H}^{++}$monkeys, including bilateral damage to the white matter located lateral to the amygdaloid complex and substantial damage to caudal visual area TEO and the posterior portion of area IE (Zola-Morgan et al., 1989c). Thus, it would not be unreasonable to suppose that on some tasks, the $\mathrm{H}^{+} \mathrm{A}^{+}$monkeys would bc more impaired than the monkeys with $\mathrm{H}^{++}$lesions.

The $\mathrm{H}^{++}$lesion produced a level of memory impairment that was sometimes comparable to the impairment observed following $\mathrm{H}^{+} \mathrm{A}^{+}$lesions. On the $10 \mathrm{~min}$ delay interval of the delayed nonmatching to sample task, the scores of the $\mathrm{H}^{++}$group were similar to the scores of the $\mathrm{H}^{+} \mathrm{A}^{+}$group [56\% vs $52 \%$, respectively; $t(6)=1.2, P>0.25$. Because the $\mathrm{H}^{+} \mathrm{A}$ group was given the delayed nonmatching to sample task only once, these comparisons are based on one test for the $\mathrm{H}^{+} \mathrm{A}^{+}$group and two tests for the $\mathrm{H}^{++}$group]. The $\mathrm{H}^{++}$group was not as impaired as the $\mathrm{H}^{+} \mathrm{A}^{+}$group when the scores on the delayed nonmatching to sample task were averaged across the three longest delays $[71 \%$ vs $61 \%$, respectively; $t(6)=3.2, P<0.05]$. On the delayed retention of object discriminations, the two groups obtained nearly identical scores (mean percentage correct across the $3 \mathrm{~d}$ of testing: $\mathrm{H}^{++}=69 \%, \mathrm{H}^{+} \mathrm{A}^{+}=70 \%$ ). On concurrent discrimination learning, the $\mathrm{H}^{+} \mathbf{A}^{+}$monkeys as a group required more trials to reach criterion level performance than the $\mathrm{H}^{++}$monkeys [1100 trials vs 578 trials, respectively; $t(6)=2.4, P<0.052$ ]. 
However, two of the monkeys in the $\mathrm{H}^{++}$group had scores that were similar to the scores of the $\mathrm{H}^{+} \mathrm{A}^{+}$group (820 and 830 trials). Two other monkeys had scores within the normal range (300 and 360 trials).

Human amnesia impairs the ability to acquire facts and events (declarative or explicit memory) but spares the capacity for certain other kinds of abilities (nondeclarative or explicit memory), including skill learning and habit learning (for review, see Squire, 1992). Thus, despite their memory impairments, the $\mathrm{H}^{++}$and the $\mathrm{H}^{+}$monkeys in the present study were entirely normal at acquiring the pattern discrimination task and at acquiring and retaining the lifesaver motor skill task. Given this framework for understanding memory function, the finding in the present study that monkey $\mathrm{H}^{++} 5$ could perform normally on all three amnesia-sensitive tasks, and the finding that two of the $\mathrm{H}^{++}$monkeys were able to perform normally on the concurrent discrimination learning task were unexpected.

One possibility is that some monkeys with large medial temporal lobe lesions can perform normally on tasks that have been shown to be sensitive to amnesia in humans because they are able to approach these tasks as tasks of habit memory or nondeclarative memory. This kind of memory does not require the integrity of the medial temporal lobe structures (Mishkin and Petri, 1984; Squire and Zola-Morgan, 1991). It is also known that monkeys will engage a habit-like strategy in tasks that humans would perform using a declarative memory strategy. For example, monkeys with $\mathrm{H}^{+} \mathbf{A}^{+}$lesions, who were severely impaired on the delayed nonmatching to sample task, performed normally on a version of the concurrent discrimination learning task that was different from the task used in the present study and that involved 20 different discrimination pairs, given once each day, always in the same order (the $24 \mathrm{hr}$ concurrent task; Malamut et al., 1984). However, amnesic patients failed this task presumably because they tried unsuccessfully to solve it by using a declarative strategy (Squire et al, 1988; Zola-Morgan and Squire, 1990).

This same perspective can be applied to the concurrent learning task used in the present study that ordinarily reveals a clear impairment in monkeys with large medial temporal lobe lesions. Two-choice discrimination tasks that require a relatively small number of trials to learn (e.g., 20-80 trials) are more sensitive to the effects of medial temporal lobe damage than are tasks that require many trials to learn (e.g., greater than 80 trials; Squire and Zola-Morgan, 1983). Normal monkeys required an average of 469 trials to learn the concurrent discrimination task used here. Thus, it is not unreasonable to suppose that a monkey with a medial temporal lobe lesion might sometimes learn this task normally. Others have also discussed the important fact that many lasks are potentially amenable to more than one memory strategy (Eichenbaum et al., 1989; Sutherland and Rudy, 1989; Squire, 1992).

In summary, the present findings suggest that the level of impairment that follows $\mathrm{H}^{++}$damage approaches the level of impairment that follows $\mathrm{H}^{+} \mathrm{A}^{+}$damage. Thus, taken together with recent neuroanatomical evidence that the perirhinal cortex and the caudally adjacent parahippocampal cortex comprise approximately $60 \%$ of the input to the entorhinal cortex (Insausti et al., 1987), these findings emphasize the importance for memory function of the hippocampal formation and the surrounding cortex of the medial temporal lobe. In particular, the present findings underscore the important contribution to memory function made by the perirhinal cortex (Horel et al., 1987;
Murray et al., 1989; Squire and Zola-Morgan, 1991; Murray, 1992).

\section{References}

Aggleton JP, Mishkin M (1983) Visual recognition impairment following medial thalamic lesions in monkeys. Neuropsychologia 21: 187-197.

Amaral DG, Insausti R, Cowan WM (1987) The monkey entorhinal cortex. I. Cytoarchitectonic organization. J Comp Neurol 264:326-355.

Eichenbaum H, Mathews P, Cohen NJ (1989) Further studies of hippocampal representation during odor discrimination learning. Behav Neurosci 103:1207-1216.

Harlow H, Bromcr JA (1938) A test-apparatus for monkcys. Psychol Rev 19:434-438.

Hartley LH, Roger R, Nicolosi RJ, Hartley T (1984) Blood pressure values in Macaca fascicularis. J Med Primatol 13:183-189.

Horel JA, Pytko-Joiner DE, Voytko M, Salsbury K (1987) The performance of visual tasks while segments of the inferotemporal cortex are suppressed by cold. Behav Brain Res 23:29-42.

Insausti R, Amaral DG, Cowan WM (1987) The entorhinal cortex of the monkey: II. Cortical afferents. J Comp Neurol 264:356-395.

Mahut H, Moss M, Zola-Morgan S (1981) Retention deficits after combined amygdalo-hippocampal resections in the monkey. Neuropsychologia 19:201-255.

Mahut H, Zola-Morgan S, Moss M (1982) Hippocampal resections impair associative learning and recognition memory in the monkey. J Ncurosci 2:1214-1229.

Malamut BL, Saunders RC, Mishkin M (1984) Monkeys with combined amygdalo-hippocampal lesions succeed in object discrimination learning despite 24-hour intertrial intervals. Behav Neurosci 98: 759-769.

Mishkin M (1978) Memory in monkeys severely impaired by combined but not separate removal of the amygdala and hippocampus. Nature 273:297-298.

Mishkin M, Petri HL (1984) Memories and habits: some implications for the analysis of learning and retention. In: Neuropsychology of memory (Squire LR, Butters N, eds), pp 287-296. New York: The Guilford Press.

Murray EA (1992) Medial temporal lobe structures contributing to recognition memory: the amygdaloid complex versus rhinal cortex. In: The amygdala: neurobiological aspects of emotion, memory, and mental dysfunction (Aggleton JP, ed), pp 453-470. London: Wiley-Liss.

Murray EA, Mishkin M (1984) Severe tactual as well as visual memory deficits follow combined removal of the amygdala and hippocampus in monkeys. J Neurosci 4:2265-2580.

Murray EA, Mishkin M (1986) Visual recognition in monkeys following rhinal cortical ablations combined with either amygdalectomy or hippocampectomy. J Neurosci 6:1991-2003.

Murray EA, Bachevalier J, Mishkin M (1989) Effects of rhinal cortical lesions on visual recognition memory in monkeys. Soc Neurosci Abstr $15: 342$.

Saunders RC, Murray EA, Mishkin M (1984) Further evidence that amygdala and hippocampus contribute equally to recognition memory. Neuropsychologia 22:785-796.

Scoville WB, Milner B (1957) Loss of recent memory after bilateral hippocampal lesions. J Neurol Neurosurg Psychiatry 20:11-21.

Squire LR (1992) Memory and the hippocampus: a synthesis from findings with rats, monkeys, and humans. Psychol Rev 99:195-231.

Squire LR, Zola-Morgan S (1983) The neurology of memory: the case for correspondence between the findings for human and nonhuman primate. In: The physiological basis of memory (Deutsch JA, ed), pp 199-268. New York: Academic Press.

Squire LR, Zola-Morgan (1988) Memory: brain systems and behavior. Trends Neurosci 4:170-175.

Squire LR, Zola-Morgan S (1991) The medial temporal lobe memory system. Science 253:1380-1386.

Squire LR, Zola-Morgan S, Chen KS (1988) Human amnesia and animal models of amnesia: performance of amnesic patients on tests designed for the monkey. Behav Neurosci 102:210-221.

Sutherland RW, Rudy JW (1989) Configural association theory: the role of the hippocampal formation in learning, memory, and amnesia. Psychobiology 17:129-144.

Suzuki WA, Zola-Morgan S, Squire LR, Amaral DG (1991) Lesions of the perirhinal and parahippocampal cortices in monkeys produce 
a modality general and long lasting memory impairment. Soc Neurosci Abstr 17:339.

Szabo J, Cowan WM (1984) A stereotaxic atlas of the brain of the cynomolgus monkey (Macaca fascicularis). J Comp Neurol 222: 265-300.

Van Hoesen GW (1982) The parahippocampal gyrus. New observations regarding its cortical connections in the monkey. Trends Neurosci 5:345-350.

Van Hoesen GW, Pandya DN (1975) Some connections of the entorhinal (area 28) and perirhinal (area 35) cortices of the rhesus monkey. III. Efferent connections. Brain Res 95:39-59.

von Bonin G, Bailey P (1947) The neocortex of Macaca mulatta. Urbana, IL: University of Illinois.

Witter MP, Groenewegen HJ, Lopes da Silva FH, Lohman AH (1989) Functional organization of the extrinsic and intrinsic circuitry of the parahippocampal region. Prog Neurobiol 33:161-253.

Zola-Morgan S, Squire LR (1984) Preserved learning in monkcys with medial temporal lesions: sparing of motor and cognitive skills. J Neurosci 4:1072-1085.

Zola-Morgan S, Squire LR (1985) Medial temporal lesions in monkeys impair memory on a variety of tasks sensitive to human amnesia. Behav Neurosci 99:22-34.

Zola-Morgan S, Squire LR (1986) Memory impairment in monkeys following lesions of the hippocampus. Behav Neurosci 100:165-170.
Zola-Morgan S, Squire LR (1990) Identification of the memory system damaged in medial temporal lobe amnesia. In: The biology of memory (Squire LR, Lindenlaub E, eds), pp 509-521. Stuttgart: Schautter.

Zola-Morgan S, Squire LR (1993) The neuroanatomy of amnesia. Ann Rev Neurosci, in press.

Zola-Morgan S, Squire LR, Mishkin M (1982) The neuroanatomy of amnesia: the amygdala-hippocampus vs. temporal stem. Science 218:1337-1339.

Zola-Morgan S, Squire LR, Amaral DG (1989a) Lesions of the hippocampal formation but not lesions of the fornix or the mammillary nuclei produce long-lasting memory impairment in monkeys. J Neurosci 9:897-912.

Zola-Morgan S, Squire LR, Amaral DG (1989b) Lesions of the amygdala that spare adjacent cortical regions do not impair memory or exacerbate the impairment following lesions of the hippocampal formation. J Neurosci 9:1922-1936.

Zola-Morgan S, Squire LR, Amaral DG, Suzuki W (1989c) Lesions of perirhinal and parahippocampal cortex that spare the amygdala and hippocampal formation produce severe memory impairment. J Neurosci 9:4355-4370.

Zola-Morgan S, Squire LR, Rempel NL, Clower RP, Amaral DG (1992) Enduring memory impairment in monkeys after ischemic damage to the hippocampus. J Neurosci 12:2582-2596. 